\title{
Peningkatan Daya Saing Lembaga Pendidikan Kemaritiman di Era Masyarakat Ekonomi ASEAN dengan Penerapan CRM
}

O T Prayitno*1

${ }^{1}$ Akademi Maritim Cilacap

E-mail: otegoohp@gmail.com*1

Masuk: 30 Agustus 2018, direvisi: 31 Agustus 2018, diterima: 31 Agustus 2018

\begin{abstract}
Abstrak. Program tol laut dan poros maritim dunia yang didengungkan pemerintah Indonesia mampu membangkitkan kembali semangat lembaga-lembaga pendidikan kemaritiman. Kebangkitan itu terjadi di tingkat SMK maupun perguruan tinggi. Lembaga-lembaga tersebut bersaing secara ketat di segala bidang termasuk profesionalitas. Persaingan dalam masalah profesionalitas terjadi karena saat ini konteks lembaga sudah bersifat modern. Kondisi ini terlihat dari perlakuan pelanggan/customer bukan sebagai objek tetapi menjadi bagian dari lembaga tersebut. Salah satu konsep populer yang ditawarkan dunia teknologi informasi melalui metode Customer Relationship Management (CRM) yaitu optimalisasi penggunaan sosial media dalam peningkatan hubungan dan keterlibatan pelanggan (customer engagement). Paper ini akan membahas penerapan CRM dalam sebuah lembaga pendidikan kemaritiman.
\end{abstract}

Kata kunci: Customer Relationship Management; CRM; poros maritim; tol laut; keterlibatan pelanggan

\begin{abstract}
Sea toll road program and world's maritime strategy bring the spirit of maritime educational institutions alive again recently. The rise takes place in vocational schools and universities. These institutions "fight" and "compete" in every aspect including proffesionalism. The competition in professionalism happens because the institutions' context has been modern. It can be seen by customers' treatment that is no longer an object but a part of the institution. One of many popular concepts offered by world's information technology is through Customer Relationship Management (CRM). It is an optimization of social media users in developing customers' relation and engagement. This research will discuss the application of CRM in maritime educational institutions.
\end{abstract}

Keywords: Customer Relationship Management; CRM; maritime axis; sea toll; customer engagement

\section{Pendahuluan}

Salah satu program dalam Nawa Cita (sembilan agenda) yang diemban pemerintahan Ir. Joko Widodo dan Jusuf Kalla adalah memperkuat jati diri Indonesia sebagai negara maritim. Dalam konteks ini, pemerintah berkeinginan mengembalikan kejayaan Indonesia sebagai negara maritim. Modal utama keinginan tersebut adalah letak geografisnya yang sangat strategis, yaitu di antara dua benua (Asia dan 
Australia) dan dua samudera (Hindia dan Pasifik). Posisi strategis Indonesia setidaknya ada dua. Pertama, sebagai negara dengan posisi strategis untuk lalu lintas laut dunia ditambah dengan luas wilayah laut mencapai 5,8 juta $\mathrm{km}^{2}$. Kedua jumlah perairan teritorial sebesar 3,1 juta $\mathrm{km}^{2}$ dan 2,7 juta $\mathrm{km}^{2}$ perairan ZEE dan memiliki 17.000 lebih pulau [1].

Besar dan kompleksnya perairan teritorial membuat banyak infrastruktur pendukung yang disiapkan. Salah satu dari banyak infrastruktur tersebut adalah kualitas sumber daya manusia yang harus dibenahi melalui sistem informasi [2] maupun dengan kanal-kanal media sosial [2]. Kondisi ini bertambah kompleks mengingat Indonesia sudah mengikuti Masyarakat Ekonomi Asean (MEA), di mana konsep pasar bebas sudah harus mulai dijalankan yang berimplikasi pada masuknya sumber daya manusia di Indonesia [3][4].

Menurut data Kementrian Pendidikan dan Kebudayaan tahun 2016, jumlah kelulusan siswa SMA baik negeri maupun swasta di seluruh Indonesia mencapai 1.423.607 siswa pada tahun ajaran 2015/2016 dan jumlah lulusan SMK yang rata-rata per tahun mencapai 1,3 juta siswa. Pada tahun ajaran 2011/2012 jumlah mahasiswa baru program diploma (S0) mencapai 148.512 orang.

Persaingan yang ketat mau tidak mau harus dihadapi oleh Akademi Maritim Nusantara (AMN) Cilacap sebagai salah satu lembaga pendidikan kemaritiman di Indonesia. Persaingan yang meraka hadapi adalah menjaring peminat untuk dididik menjadi insan maritim yang mumpuni. Metode yang tepat dan mengikuti perkembangan pun tidak bisa dikesampingkan, diantaranya penerapan Customer Relationship Management [5][6]. Penggunaan CRM di berbagai bidang usaha bertujuan untuk memuaskan pelanggan sehingga mereka bisa bertahan sebagai pelanggan untuk suatu usaha tertentu [7][8]. Di sisi lain guna mengembangkan hal tersebut pengembangan strategis sumber daya manusia harus dilakukan. Penggunaan berbasis pada karakteristik manusia perlu dipertimbangkan contohnya motivasi, rekrutmen, pembayaran, promosi dan lain sebagainya [9].

\section{Pengumpulan dan Analisa Data}

Data yang digunakan sebagai acuan adalah peminatan calon taruna dan jumlah taruna yang diterima selama rentang waktu 2010 - 2016. Berdasarkan data yang didapat dari BAAK (Biro Administrasi Akademik dan Kemahasiswaan), berikut adalah data peminatan dan yang diterima sebagai taruna di AMN Cilacap. Analisa dilakukan dengan melihat tren data dan perbandingannya antara data peminatan dan data penerimaan mahasiswa selama enam tahun. Dari perbandingan diharapkan pola tren dapat diasosiasikan dengan kondisi nyata kaitannya program yang dilakukan selama jangka waktu tersebut [10].

1. Program Studi Teknik Mesin Kapal

Tabel 1 menunjukkan statistik pendaftaran Taruna Baru Akademi Maritim Nusantara Program

Studi Teknik Mesin Kapal pada tahun ajaran 2010 - 2016.

Tabel 1. Statistik Pendaftaran Taruna Baru Prodi Teknik Mesin Kapal TA. 2010 - 2016

\begin{tabular}{ccccc}
\hline Tahun Akademik & Pendaftar & Ikut Seleksi & Lulus Seleksi & Mahasiswa Baru \\
\hline $2010 / 2011$ & 71 & 71 & 68 & 68 \\
$2011 / 2012$ & 94 & 94 & 87 & 86 \\
$2012 / 2013$ & 118 & 118 & 109 & 109 \\
$2013 / 2014$ & 110 & 110 & 94 & 94 \\
$2014 / 2015$ & 120 & 120 & 97 & 97 \\
$2015 / 2016$ & 113 & 113 & 96 & 96 \\
$2016 / 2017$ & 126 & 126 & 91 & 91 \\
\hline
\end{tabular}

2. Program Studi Nautika

Tabel 2 menunjukkan statistik pendaftaran Taruna Baru Akademi Maritim Nusantara Program Studi Nautika pada tahun ajaran 2010 - 2016. 
Tabel 2. Statistik Pendaftaran Taruna Baru Prodi Nautika TA. 2010 - 2016

\begin{tabular}{ccccc}
\hline Tahun Akademik & Pendaftar & Ikut Seleksi & Lulus Seleksi & Mahasiswa Baru \\
\hline $2010 / 2011$ & 68 & 66 & 66 & 66 \\
$2011 / 2012$ & 76 & 76 & 63 & 63 \\
$2012 / 2013$ & 110 & 110 & 97 & 97 \\
$2013 / 2014$ & 67 & 67 & 50 & 50 \\
$2014 / 2015$ & 86 & 86 & 71 & 71 \\
$2015 / 2016$ & 94 & 94 & 83 & 83 \\
$2016 / 2017$ & 105 & 105 & 89 & 89 \\
\hline
\end{tabular}

3. Program Studi Pengelolaan Pelabuhan

Tabel 3 menunjukkan statistik pendaftaran Taruna Baru Akademi Maritim Nusantara Program Studi Pengelolaan Pelabuhan pada tahun ajaran 2011 - 2016.

Tabel 3. Statistik Pendaftaran Taruna Baru Prodi Pengelolaan Pelabuhan TA 2011 - 2016

\begin{tabular}{ccccc}
\hline Tahun Akademik & Pendaftar & Ikut Seleksi & Lulus Seleksi & Mahasiswa Baru \\
\hline $2011 / 2012$ & 103 & 103 & 84 & 84 \\
$2012 / 2013$ & 154 & 154 & 139 & 139 \\
$2013 / 2014$ & 153 & 153 & 138 & 138 \\
$2014 / 2015$ & 189 & 189 & 171 & 171 \\
$2015 / 2016$ & 228 & 228 & 189 & 189 \\
$2016 / 2017$ & 250 & 250 & 170 & 170 \\
\hline
\end{tabular}

\section{Hasil dan Pembahasan}

CRM adalah upaya penggunaan media sosial secara optimal untuk menunjang peningkatan kinerja, produksi dan/atau pelayanan sebuah organisasi kepada pelanggan dengan melibatkan pelanggan itu sendiri untuk berperan di dalamnya. Keterlibatan pelanggan ini difasilitasi dengan teknologi informasi untuk dapat dianalisa data dan siklus hidup interaksinya. Metode ini sudah diterapkan oleh beberapa perusahaan yang memproduksi barang atau jasa komersial dan sangat mungkin untuk diadopsi ke lembaga pendidikan, khususnya lembaga perguruan tinggi yang fokus pada pendidikan kemaritiman seperti Akademi Maritim Nusantara Cilacap.

Maka dari itu, perlu dilakukan langkah-langkah agar penerapan CRM ini dapat berhasil atau membuahkan hasil seperti yang diinginkan, diantaranya yaitu:

1. Identifikasi keinginan pelanggan

2. Mengutamakan pelanggan sebagai subjek

3. Memakai sudut pandang pelanggan sebagai tolok ukur

4. Membangun proses dari ujung ke ujung

5. Menyediakan layanan dukungan bagi pelanggan yang baik

6. Penanganan keluhan/komplain yang baik

7. Mencatat dan menganalisa semua aspek

Langkah-langkah di atas tidak akan berhasil jika lembaga tidak mempersiapkan hal-hal seperti: perencanaan bisnis yang matang/baik, menetapkan tujuan dan target dari penerapan CRM ini, membuat batasan sesuai strategi, membuat parameter dan ukuran keberhasilan, membuat standar aturan penanganan strategi seperti perbaikan, perubahan dan memantapkan strategi berdasar informasi yang diterima dari sistem.

Beberapa aktivitas yang bisa dilakukan dalam penerapan CRM ini antara lain:

1. Membangun basis data yang baik

Basis data yang dibangun dan dikembangkan dengan baik dapat digunakan untuk mengukur 'nilai jual' lembaga di masa sekarang dan potensinya di masa yang akan datang. Cara yang bisa dilakukan antara lain dengan pengumpulan data dari relasi dengan perusahaan, orang tua/wali taruna maupun alumni. 
2. Membuat profil pelanggan/customer

Profil pelanggan ini merupakan pencatatan aktivitas terutama perusahaan-perusahaan yang menggunakan lulusan Akademi Maritim Nusantara Cilacap. Pembuatan profil pelanggan bisa dibedakan menjadi dua, yaitu usage dan uses. Usage adalah seberapa banyak pelanggan menggunakan 'produk' dan layanan AMN Cilacap, layanan apa yang digunakan, kapan menggunakannya dan lulusan jurusan apa yang diserap/digunakan. Uses adalah menyangkut bagaimana pelanggan menggunakan 'produk' atau layanan AMN Cilacap.

3. Analisa profitabilitas tiap pelanggan

Analisa ini menyangkut hasil yang diterima (revenue) dan biaya untuk melayani pelanggan (cost). Sedikit berbeda dengan perusahaan yang memproduksi barang, di sini AMN Cilacap bisa mengartikan revenue sebagai keuntungan dalam bentuk lain, misalnya maksimalnya penyerapan lulusan di perusahaan-perusahaan partnership dan diharapkan alumni yang terserap akan menjadi nilai jual bagi AMN Cilacap [11].

4. Interaksi dengan pelanggan yang ditargetkan dengan penyesuaian

Pembuatan profil yang baik dan jelas mengenai pelanggan akan memudahkan AMN Cilacap untuk mengidentifikasi kebutuhan pelanggan yang berbeda-beda. AMN Cilacap dapat dengan mudah melayani, memberikan penawaran tentang produk dan layanan yang disesuaikan kebutuhan setiap pelanggan. AMN Cilacap dapat melayaninya secara lebih personal dan disesuaikan. Dengan cara ini, pelanggan akan merasa diperlakukan istimewa sehingga menunjang proses kepuasan pelanggan. Dalam jangka waktu tertentu bisa menimbulkan loyalitasnya [7][12].

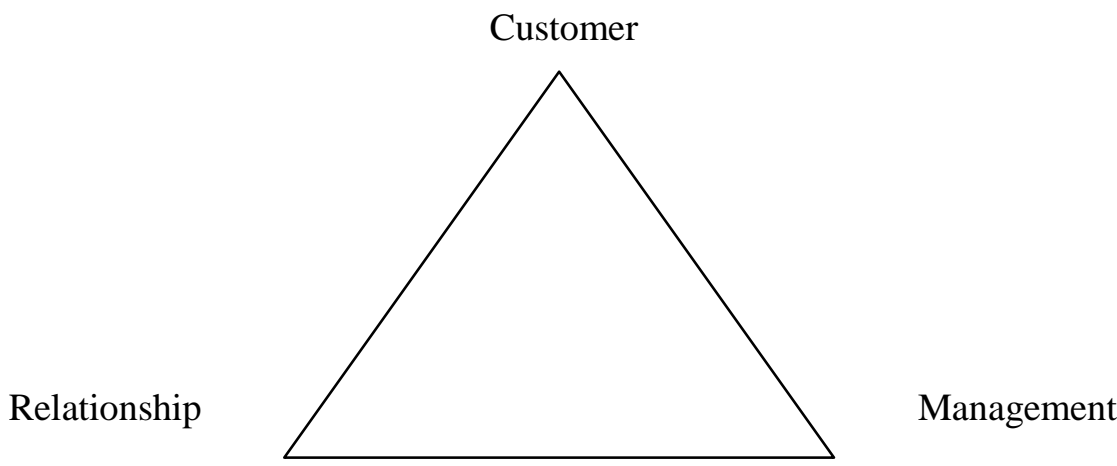

Gambar 1. Komponen CRM[13]

Komponen CRM tersaji dalam gambar 1. Customer atau pelanggan adalah satu-satunya sumber keuntungan di masa kini dan yang akan datang. Namun, kadang sulit untuk membedakan mana yang merupakan pelanggan nyata karena keputusan belanja kerap merupakan aktivitas kolaborasi antara peserta dalam proses pengambilan keputusan. Teknologi informasi dapat menyediakan kemampuan untuk membedakan dan mengelola pelanggan. CRM dapat ditempatkan sebagai pendekatan pemasaran yang didasarkan pada informasi pelanggan [13].

Relationship atau hubungan antara perusahaan (dalam hal ini AMN Cilacap) dengan pelanggan yang melibatkan komunikasi dua arah dan interaksi yang berkelanjutan (terus menerus) baik dalam jangka pendek maupun jangka panjang. Perilaku pelanggan terhadap produk atau layanan sifatnya sangat situasional walaupun memiliki sikap positif dengan perusahaan/lembaga, misalnya seperti lapangan kerja apa yang memiliki prospek bagus untuk mendapatkan penghidupan yang layak menurut standar mereka akan mempengaruhi pilihan terhadap perguruan tinggi apa yang dapat mendidik untuk menuju ke sana. CRM bukan hanya kegiatan bagian pemasaran/humas, melainkan 
juga perubahan perusahaan/lembaga secara terus-menerus. Informasi pelanggan dikumpulkan dan diubah menjadi pengetahuan yang mengarah pada kegiatan memanfaatkan informasi dan peluang.

\section{Kesimpulan dan Saran}

\subsection{Kesimpulan}

CRM adalah kegiatan pengelolaan hubungan antara perusahaan/lembaga. Dalam hal ini, AMN Cilacap dengan pelanggan (orang tua/wali, taruna, alumni dan perusahaan partner) dengan tujuan lembaga memiliki nilai tambah dan nilai jual yang lebih baik dari waktu ke waktu karena adanya interaksi dan komunikasi yang terjalin dengan baik sehingga pelanggan bersedia memberikan informasi dan informasi ini dikumpulkan untuk dianalisa dan diolah secara efektif dan efisien. Lembaga dituntut mau berubah dan selalu menyesuaikan diri dengan perubahan yang terjadi dari sudut pelanggan. Pembenahan SDM dan manajemen selalu dilakukan agar penerapan CRM dapat berjalan sebagaimana mestinya.

\subsection{Saran}

Dalam era pasar bebas dan persaingan lembaga pendidikan kemaritiman yang semakin sengit, tidak bisa dipungkiri jika pelanggan tidak bisa lagi hanya dijadikan objek, tetapi juga sebagai subjek. Alangkah baiknya jika CRM bisa dijadikan acuan untuk diterapkan terutama ketika AMN Cilacap akan melangkah untuk menjadi Sekolah Tinggi Maritim.

\section{Referensi}

[1] N. W. Deriani, "Analisa Perancangan Model Customer Relationship Management Pada STMIK STIKOM Bali," CSRID (Computer Sci. Res. Its Dev. Journal), vol. 8, no. 2, pp. 73-85, 2016.

[2] R. A. Setiawan and D. B. Setyohadi, "Understanding customers ' intention to use social network sites as complaint channel : an analysis of young customers ' perspectives," in The 2nd International Conference on Energy, Environmental and Information System (ICENIS 2017), 2018.

[3] R. Winantyo, S. Arifin, R. A. Djaafara, and A. S. Budiman, Masyarakat Ekonomi ASEAN 2015; Memperkuat Sinergi ASEAN di Tengah Kompetisi Global. Jakarta: PT. Elex Media Komputindo, 2008.

[4] D. Wuryandani, "Peluang dan Tantangan SDM Indonesia Menyongsong Era Masyarakat Ekonomi ASEAN," Info Singk. Ekon. dan Kebijak. Publik, vol. 6, no. 17, pp. 13-16, 2014.

[5] T. Coltman, T. M. Devinney, and D. F. Midgley, "Customer relationship management and firm performance," J. Inf. Technol., 2011.

[6] M. Reimann, O. Schilke, and J. S. Thomas, "Customer relationship management and firm performance: The mediating role of business strategy," J. Acad. Mark. Sci., 2010.

[7] J. Boby Setiawan Putra and D. D. Rahayu, "Pengaruh Experiential Marketing Dan Brand Trust Terhadap Kepuasan Pelanggan Dan Loyalitas Pelanggan Hotel Aryaduta Di Pekanbaru," J. Online Mhs. Fak. Ekon. Univ. Riau, vol. 4, no. 1, pp. 45-59, 2017.

[8] A. Scherer, N. V. Wünderlich, and F. von Wangenheim, "The Value of Self-Service: LongTerm Effects of Technology-Based Self-Service Usage on Customer Retention," MIS Q., 2015.

[9] M. R. Noruzi, "Human Resource Management and Customer Relationship Management (HRM \& CRM)," Soc. Sci. Res. Netw., 2007.

[10] S. Loeb, S. Dynarski, D. McFarland, P. Morris, S. Reardon, and S. Reber, "Descriptive Analysis in Education: A Guide for Researchers," (NCEE 2017-4023). U.S Dep. Educ. Inst. Educ. Sci. Natl. Cent. Educ. Eval. Reg. Assist., 2017.

[11] I. P. Artaya and I. G. Arimbawa, "Penerapan Metode Korelasi dalam Mengukur Hubungan antara Customer Relationship dengan Customer Loyality Pada PT Antika Raya Surabaya," BISMA (Bisnis dan Manajemen), vol. 1, no. 1, pp. 50-63, 2018. 
[12] D. T. Absari, "Analisis dan Desain Sistem Mananejemen Hubungan Pelanggan dengan menerapkan Konsep Recency Frequency Spending menggunakan Metode Simple Multi Attribute Rating Technique (Studi Kasus pada Perusahaan Keramik X Pasuruan)," 5th Appl. Bus. Eng. Conf., 2017.

[13] G. A. Wyner, "Customer relationship measurement," Mark. Res., vol. 11, no. 2, pp. 39-41, 1999. 